\title{
Soil erosion evolution and spatial correlation analysis in a typical karst geomorphology using RUSLE with GIS
}

\author{
Cheng Zeng ${ }^{1,2,3}$, Shijie Wang ${ }^{1,3}$, Xiaoyong Bai ${ }^{1,3}$, Yangbing $\mathbf{L i}^{2}$, Yichao Tian ${ }^{1,3}$, Yue $\mathbf{L i}^{4}$, Luhua $\mathbf{W u}^{1,3}$, and \\ Guangjie Luo ${ }^{3,5}$ \\ ${ }^{1}$ State Key Laboratory of Environmental Geochemistry, Institute of Geochemistry, Chinese Academy of Sciences, \\ 99 Lincheng West Road, Guiyang 550081, Guizhou Province, PR China \\ ${ }^{2}$ School of Geographyical and Environmental Sciences, Guizhou Normal University, Guiyang 550001, China \\ ${ }^{3}$ Puding Karst Ecosystem Observation and Research Station, Chinese Academy of Sciences, Puding 562100, \\ Guizhou Province, PR China \\ ${ }^{4}$ Key Laboratory of State Forestry Administration on Soil and Water Conservation, Beijing Forestry University, \\ Beijing 100083, China \\ ${ }^{5}$ Institute of Agricultural Ecology and Rural Development, Guizhou Normal College, Guiyang 550018, China
}

Correspondence to: Xiaoyong Bai (baixiaoyong@126.com)

Received: 6 January 2017 - Discussion started: 16 January 2017

Revised: 27 May 2017 - Accepted: 30 May 2017 - Published: 3 July 2017

\begin{abstract}
Although some scholars have studied soil erosion in karst landforms, analyses of the spatial and temporal evolution of soil erosion and correlation analyses with spatial elements have been insufficient. The lack of research has led to an inaccurate assessment of environmental effects, especially in the mountainous area of Wuling in China. Soil erosion and rocky desertification in this area influence the survival and sustainability of a population of 0.22 billion people. This paper analyzes the spatiotemporal evolution of soil erosion and explores its relationship with rocky desertification using GIS technology and the revised universal soil loss equation (RUSLE). Furthermore, this paper analyzes the relationship between soil erosion and major natural elements in southern China. The results are as follows: (1) from 2000 to 2013, the proportion of the area experiencing micro-erosion and mild erosion was at increasing risk in contrast to areas where moderate and high erosion are decreasing. The area changes in this time sequence reflect moderate to high levels of erosion tending to convert into micro-erosion and mild erosion. (2) The soil erosion area on the slope, at $15-35^{\circ}$, accounted for $60.59 \%$ of the total erosion area, and the corresponding soil erosion accounted for $40.44 \%$. (3) The annual erosion rate in the karst region decreased much faster than in the non-karst region. Soil erosion in all of the rock outcrop areas indicates an improving trend, and dynamic changes in
\end{abstract}

soil erosion significantly differ among the various lithological distribution belts. (4) The soil erosion rate decreased in the rocky desertification regions, to below moderate levels, but increased in the severe rocky desertification areas. The temporal and spatial variations in soil erosion gradually decreased in the study area. Differences in the spatial distribution between lithology and rocky desertification induced extensive soil loss. As rocky desertification became worse, the erosion modulus decreased and the decreasing rate of annual erosion slowed.

\section{Introduction}

Soil erosion is one of the most serious environmental problems that affect the environment and human development worldwide (Higgitt, 1993; Martínez-Casasnovas et al., 2016; Borrelli et al., 2016). It not only causes a loss of soil nutrients and land degradation, but also exacerbates the occurrence of droughts, floods, landslides and other disasters (Munodawafa, 2007; Park et al., 2011; Rickson, 2014; Arnhold et al., 2014). Severe soil erosion directly influences the development, application, and protection of regional resources (Cai and Liu, 2003; Ligonja and Shrestha, 2015). In 
particular, soil erosion threatens ecological security patterns at regional and even global scales.

Many factors affect the evolution of soil erosion in karst areas (Karamesouti et al., 2016; Krklec et al., 2016; Y. B. Li et al., 2016; Wang et al., 2016; Wu et al., 2016) because of the complicated natural conditions (Bai et al., 2013a, b; Tian et al., 2016). Therefore, it is necessary for ecology and soil erosion research in karst areas to explore the spatial evolution characteristics of soil erosion and their influencing factors in a karst area. In the context of global soil erosion and land degradation, traditional methods, such as runoff plots and watershed hydrological stations, are inapplicable for the study of soil erosion in karsts. This has caused fundamental research on soil erosion to lag behind that on soil and water conservation in karst areas.

China possesses the most concentrated, widely distributed, and complex areas of karst landforms worldwide. Guizhou Province is in the center of the karst landform, which is a typical representation of southern China. Due to the slow soil formation rate, mismatched water and soil space, specific geological and hydrological background, and underground structure (Wang and Li, 2007) in the karst zone, soil erosion in the area is more complex and unique than in the nonkarst zone. Soil erosion in the karst area exhibits a complex relationship with topography, lithology, and rocky desertification. In addition to surface soil loss, underground leakage has been observed in the area. The karst area has minimal environmental capacity and low restorability of the ecological system (Wallbrink et al., 2002). As such, soil erosion in the area leads to serious consequences that may restrict the sustainable development of the local economy in the region.

Many scholars have studied soil erosion and determined its causes and spatial evolution. Erosion force (Bai and Wan, 1998; Feng et al., 2011), erosion processes (Edgington et al., 1991; Cao et al., 2012), soil degradation (M. Feng et al., 2016; Gao et al., 2015; Guo et al., 2015), and erosion mechanisms (Hancock et al., 2014) have also been explored. Studies on soil erosion have been mainly concentrated in non-karst areas or basins (Fernández and Vega, 2016; Park et al., 2011), whereas few studies have investigated the fragile ecological-geological environment within the karst zone. Some scholars have also conducted preliminary studies on soil erosion in the karst landform areas. For example, Y. Li et al. (2016) evaluated soil erosion in a typical karst basin by using the RUSLE model and explored the influence of slope on the temporal and spatial evolution laws of soil erosion in a karst area. The results indicated that the main erosion on the slope section in the basin was within $8-25^{\circ}$. Yang et al. (2014) analyzed soil erosion in Chaotiangong County in Guilin using an analytic hierarchy and fuzzy model; they found that the risk of soil erosion was very high in the southeastern study area but relatively low in the northwest. Biswas and Pani (2015) studied soil erosion in the Barakar River basin in eastern India using the RUSLE model combined with GIS technology; the soil erosion rate is more than
$100 \mathrm{t} \mathrm{km}^{-2} \mathrm{a}^{-1}$, which accounts for only $0.08 \%$ of the total study area. T. Feng et al. (2016) compared the soil erosion rate between two karst peak-cluster depression basins in northwestern Guangxi, China, using ${ }^{137} \mathrm{Cs}$ and RUSLE models. Runoff discontinuity and underground seepage on the karst slope are significant factors to consider in the RUSLE model because they reduce the effect of slope length. However, previous research exhibits some deficiencies and limitations. Most studies are conducted in karst basins or mountain areas (Shi et al., 2004; Terranova et al., 2009) and analyze the effect of terrain, rainfall, vegetation cover, and other factors on soil erosion (M. Feng et al., 2016; Ganasri and Ramesh, 2016; Liu et al., 2016). The effects of soil erosion on rocky desertification and lithology have been ignored. Few scholars have analyzed the soil erosion evolution in a karst valley area on a long time sequence or determined the effect of spatial factors on evolution. Therefore, the available data on the correlation between soil erosion evolution and spatial factors in the karst zone are limited, particularly for the mountainous area of Wuling, China. This lack of knowledge leads to an inaccurate assessment of the environmental effects in the region; soil erosion and rocky desertification in this area influence the survival and development of 0.22 billion people. Studying the evolution of the temporal and spatial distribution of soil erosion in the karst area and analyzing its correlation with spatial factors remains challenging. Studies have rarely been conducted worldwide because of a lack of supporting data, insufficient experience, and lack of applicable technical methods.

This paper evaluated typical karst areas in southern China and combined current surveys on soil types with calculation results from a soil erodibility test. Soil erosion was analyzed in different periods using a revised universal soil loss equation (RUSLE) model. The specific aims of this study were as follows: (1) to identify the evolution of the temporal and spatial distribution of soil erosion in typical karst areas in southern China; (2) to explore the relationship between soil erosion and rocky desertification; and (3) to determine the correlation between soil erosion and major natural elements and evaluate their ecological effect. This study improved upon existing research methods and proposes suggestions for additional research. It provides a basis for macrodecision-making by government policy makers and environmental managers as well as relevant data on methodology and references for research into soil erosion in karst landform areas.

\section{Study area}

Yinjiang County is located on the northeastern Guizhou Plateau (China); the geographical position of the study area is $108^{\circ} 17^{\prime}$ to $108^{\circ} 48^{\prime} \mathrm{N}, 27^{\circ} 35^{\prime}$ to $28^{\circ} 28^{\prime} \mathrm{E}$ and the land area is $196900 \mathrm{hm}^{2}$. Mount Fanjing, the main peak in the Wuling Mountains, is located in the east of Yinjiang. The topogra- 

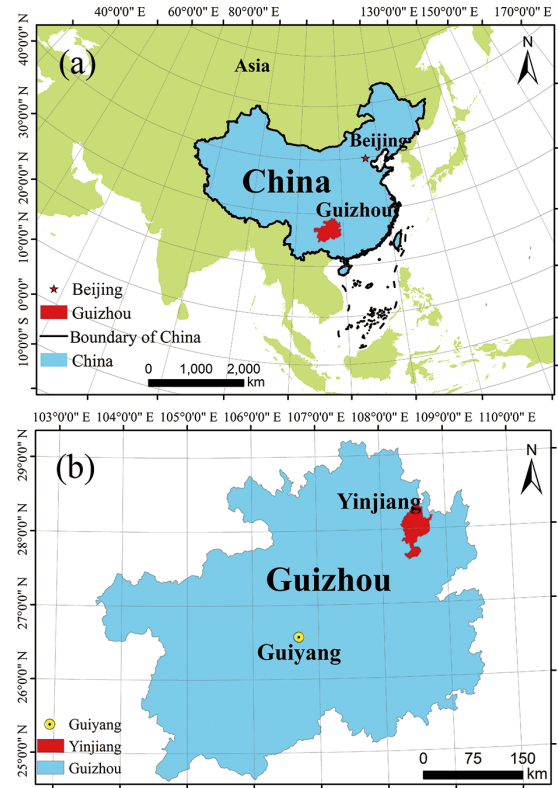

$108^{\circ} 20^{\prime} 0^{\prime \prime} \mathrm{E} \quad 108^{\circ} 30^{\prime} 0^{\prime \prime} \mathrm{E} \quad 108^{\circ} 40^{\prime} 0^{\prime \prime} \mathrm{E} \quad 108^{\circ} 50^{\prime} 0{ }^{\prime \prime} \mathrm{E}$

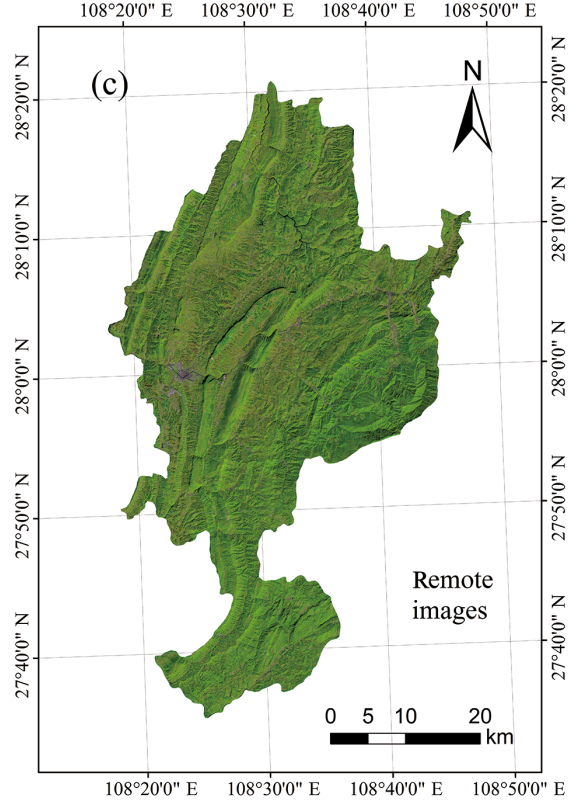

$108^{\circ} 20^{\prime} 0^{\prime \prime}$ E $\quad 108^{\circ} 30^{\prime} 0^{\prime \prime} \mathrm{E} \quad 108^{\circ} 40^{\prime} 0^{\prime \prime} \mathrm{E} \quad 108^{\circ} 50^{\prime} 0^{\prime \prime} \mathrm{E}$

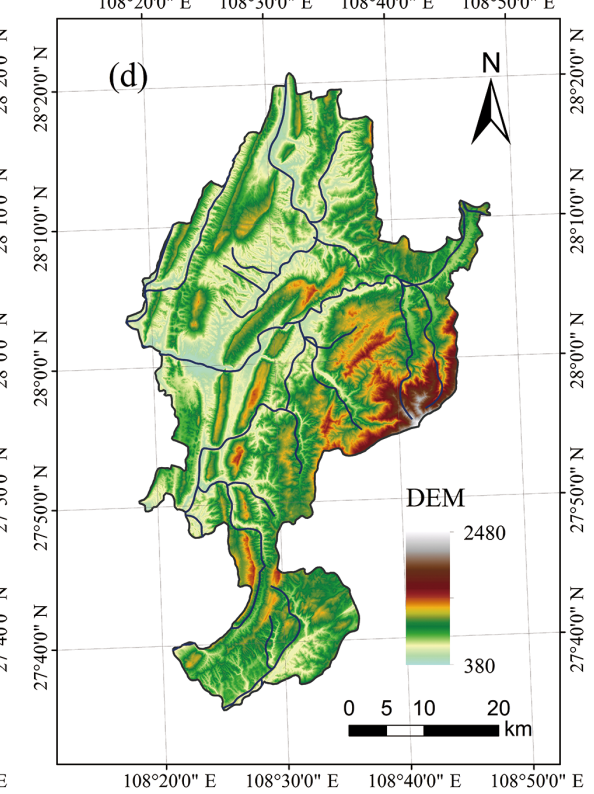

Figure 1. Study area in Guizhou, China (a, b). Study area remote images (c) and topography (d).

phy is such that the east is at a high elevation and the west is at a low elevation, sloping from southeast to northwest. Yinjiang County has a relative elevation difference of $2000 \mathrm{~m}$ and an average altitude of $2480 \mathrm{~m}$ (Fig. 1). The study area has a subtropical monsoonal climate with annual precipitation of $1100 \mathrm{~mm}$. Rainfall occurs mainly between April and August. The temperature in this area ranges from -3.1 to $29.8^{\circ} \mathrm{C}$ with an annual average of $16.8^{\circ} \mathrm{C}$. The highest monthly temperature occurs in July, and the lowest occurs in January. The vegetation is primarily composed of evergreen broad-leaved forest, coniferous forest, evergreen deciduous broad-leaved mixed forest, and temperate coniferous mixed forest. The vegetation coverage increased from 49.1 to $58.5 \%$ during the study period.

Carbonate rocks are widely distributed in Yinjiang County, accounting for $60.06 \%$ of the total area (Fig. 2b). During karst activity, the mantle rock is discontinuous with underground fissures and karst development. Widely distributed soil erosion led to a thin soil layer in the study area and a fragile ecology. Yinjiang County has suffered from different degrees of rocky desertification, accounting for $57.69 \%$ of the total area of the whole county (Fig. 2c). Rocky desertification has been mainly caused by soil erosion due to unsustainable land use. According to the classification of soil zonality, the zonal soil is yellow soil in the study area, but a large area is distributed with lime soil. Moreover, based on the site survey, mountain shrub meadow soil, soil mud, a purple mud field, a tidal sand mud field, and other soil types are distributed in Yinjiang (Fig. 1a). All of these factors are dominant in a typical karst area.

\section{Materials and methods}

\subsection{Data sources}

The related data collected based on the RUSLE model mainly include the following: (1) monthly rainfall data in the study area for 2000, 2005, and 2013 from the Tongren Meteorological Bureau (http://tongren04264.11467.com). (2) A soil database was established according to a current survey of soil types, particle size, and the content of organic substances in various soil types that are mainly based on Chinese soil records. (3) A digital elevation model (DEM) was obtained from a Chinese remote-sensing satellite ground station at the Chinese Academy of Sciences (http://www.cas.cn), with a spatial resolution of $30 \mathrm{~m}$. (4) ArcGIS 10.0 was used to determine the three study periods of the NDVI data from the Chinese geospatial data cloud platform (http://www.gscloud.cn). (5) Landsat 7 OLI and Landsat 8 OLI remote sensing images (P126, R40 and P126, R41) were synthesized in ArcGIS 10.0 for stitching and cutting using the data from the Chinese geospatial data cloud platform, with a spatial resolution of $30 \mathrm{~m}$; based on these data, a land-use map was drawn in ArcGIS 10.0 software. The Albers equal-area conic projection was used for a geographic coordinate system.

\subsection{RUSLE model}

The RUSLE model (Renard et al., 1997) is an empirical model revised from the USLE model for predicting soil erosion. The calculation is as follows:

$A=R \times K \times L \times S \times C \times P$, 

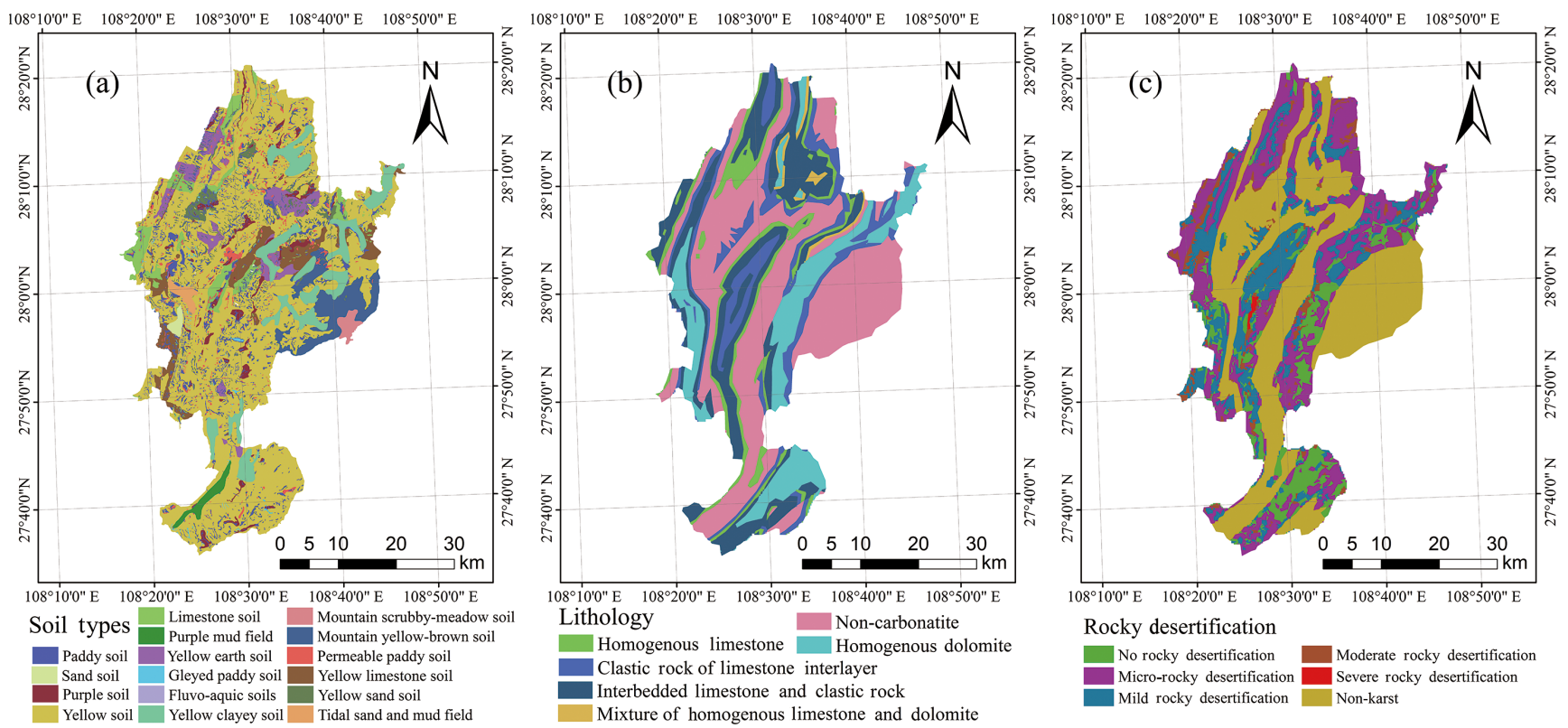

Figure 2. Study area geological background: soil map (a), lithology (b), and rocky desertification (c).

where $A$ [US unit $\mathrm{t} \mathrm{km}^{-2} \mathrm{a}^{-1}$ ] refers to the amount of soil loss per unit area in time and space and depends on the $K$ and $R$ units. $R\left[\mathrm{MJ} \mathrm{mm}\left(\mathrm{hm}^{2} \mathrm{~h} \mathrm{a}\right)^{-1}\right]$ refers to the rainfall erosivity factor in consideration of the erosion of snowmelt runoff. $K\left[\mathrm{thm}^{2} \mathrm{~h}\left(\mathrm{hm}^{2} \mathrm{MJ} \mathrm{mm}\right)^{-1}\right]$ refers to the soil erodibility factor, which is the soil loss rate of specific soil rainfall erosivity per unit measured in a standard plot. $L$ and $S$ refer to the slope aspect factor. $C$ refers to the coverage factor for vegetation. $P$ refers to the conservation measure factor, which includes engineering and tillage measure factors.

\subsubsection{Rainfall erosivity factor $(R)$}

Rainfall erosivity represents the potential ability of rainfall to induce erosion. Rainfall erosivity is the primary factor that should be considered in the soil loss equation and is related to rainfall, duration of rainfall, and rainfall energy. This factor reflects the effect of rainfall characteristics on soil erosion. Rainfall erosivity is difficult to directly measure. Most studies use rainfall parameters, including rainfall intensity and precipitation, to estimate rainfall erosivity. Given the relatively fragmented surface, concentrated precipitation, and strong water erosion in the study area, this paper adopts a simple monthly rainfall formula developed by Zhou et al. (1995) to estimate rainfall erosivity $(R)$ in Yinjiang by comparing various algorithms and determining the accuracy of the acquired climate data. The formula is as follows:

$R=\sum_{i=1}^{12}\left(-1.5527+0.7297 P_{i}\right)$ where $P_{i}$ refers to the rainfall in month $i(\mathrm{~mm})$. The unit of the calculated $R$ is $100 \mathrm{ft} \mathrm{tin} \mathrm{ac}{ }^{-1} \mathrm{~h}^{-1} \mathrm{a}^{-1}$. If $R$ is changed to the international unit $\mathrm{MJ} \mathrm{mm} \mathrm{hm}{ }^{-2} \mathrm{~h}^{-1} \mathrm{a}^{-1}$, then a coefficient of 17.02 should be the multiplier (Table 1).

\subsubsection{Soil erodibility factor $(K)$}

Soil erodibility is an important indicator that reflects the rainfall infiltration capacity of soil and the sensitivity of soil to rainfall and runoff erosion. This internal factor affects soil loss. The size of $K$ is related to the soil texture and organic material content. In this paper, soil erodibility and soil mechanical composition are used to form a calculation and are closely related to the organic carbon content (Sharpley and Williams, 1990):

$$
\begin{aligned}
K= & \left\{0.2+0.3 \exp \left[-0.0256 \mathrm{SAN}\left(1-\frac{\mathrm{SIL}}{100}\right)\right]\right\} \\
& \times\left(\frac{\mathrm{SIL}}{\mathrm{CLA}-\mathrm{SIL}}\right) \\
& \times\left(1-\frac{0.3 \mathrm{SN} 1}{\mathrm{SN} 1+\exp (-5.51+22.9 \mathrm{SN} 1)}\right),
\end{aligned}
$$

where $K$ refers to the soil erodibility [(t acre h) $\left.(100 \text { acre } \mathrm{ft} \operatorname{tanf} \text { in })^{-1}\right]$. A conversion factor of 0.1317 should be multiplied to obtain the international unit $\left(\mathrm{thm}^{2} \mathrm{~h}\right)\left(\mathrm{hm}^{2} \mathrm{MJ} \mathrm{mm}\right)^{-1}$. SAN, SIL, CLA, and $C$ refer to the sand particles $(0.050-2.000 \mathrm{~mm})$, powder particles $(0.002-0.050 \mathrm{~mm})$, clay particles $(<0.002 \mathrm{~mm})$, and organic material content $(\%) ; \mathrm{SN} 1=1-\mathrm{SN} / 100$. Different $K$ (Fig. 3a) values are obtained from the different soil types on the soil type map (Fig. 2a). 

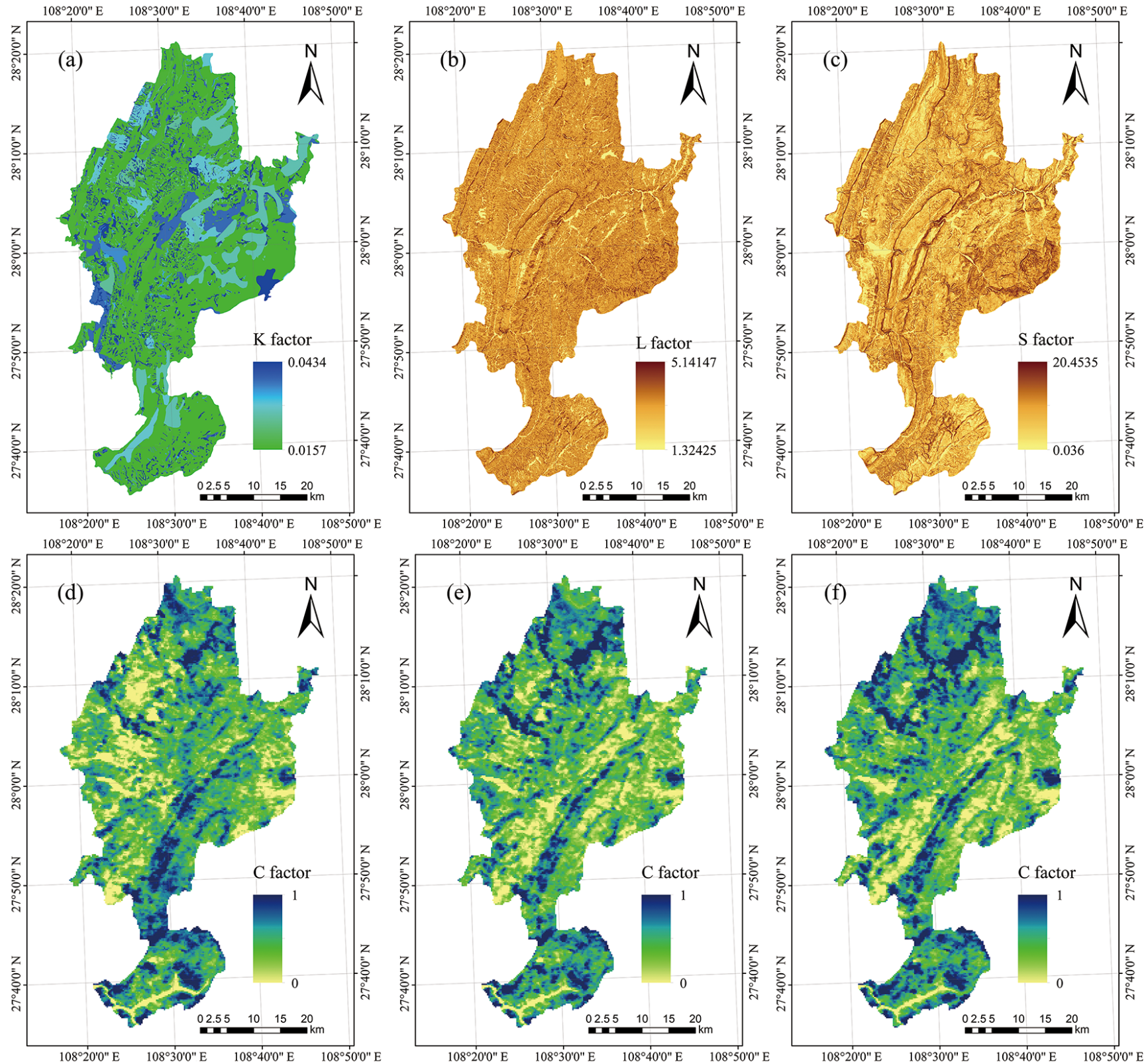

Figure 3. Soil erodibility map (a), slope length factor map (b), slope gradient factor map (c), 2000 vegetation cover factor map (d), 2005 vegetation cover factor map (e), and 2013 vegetation cover factor map (f).

\subsubsection{Topographic factor $(L)(S)$}

Slope length is a basic terrain factor that influences soil erosion. In this paper, the formula developed by Liu et al. (2000) is used to calculate slope length in Yinjiang County. The calculation is as follows:

$$
\begin{aligned}
& S= \begin{cases}10.8 \sin \theta+0.03 & \theta \triangleleft 5^{\circ} \\
16.8 \sin \theta-0.05 & 5^{\circ} \leq \theta \triangleleft 10^{\circ} \\
21.9 \sin \theta-0.96 & \theta \geq 10^{\circ},\end{cases} \\
& L=(\lambda / 22.13)^{m},
\end{aligned}
$$

where $S$ refers to the slope factor, $\theta$ refers to the slope value $\left.{ }^{\circ}\right), L$ refers to the slope length factor, and $\lambda$ refers to the slope length $(\mathrm{m})$. To determine the slope and length, $30 \mathrm{~m}$ DEM data from ArcGIS are used and then placed in the formula to calculate $L, S$ (Fig. $3 \mathrm{~b}$ and c).

\subsubsection{Vegetation cover factor $(C)$}

The vegetation cover is correlated with $C$; hence, this paper used the NDVI of MODIS as a data resource for calculating the vegetation coverage factor $C$ using the methods of Cai et 
Table 1. The rainfall erosivity factor $(R)$ in Yinjiang during the study period.

\begin{tabular}{rrr}
\hline Year & $\begin{array}{r}\text { Annual rainfall } \\
(\mathrm{mm})\end{array}$ & $\begin{array}{r}\text { Annual rainfall erosivity } \\
{\left[\mathrm{MJ} \mathrm{mm} \mathrm{hm} \mathrm{mm}^{-2} \mathrm{~h}^{-1} \mathrm{a}^{-1}\right]}\end{array}$ \\
\hline 2000 & 1121.03 & 3183.25 \\
2005 & 884.23 & 2460.92 \\
2013 & 734.39 & 2003.93 \\
\hline
\end{tabular}

al. (2000). The vegetation coverage rate is also determined using the algorithm established by Tan et al. (2005) with the following equations:

$$
\begin{aligned}
& C= \begin{cases}1 & f_{\mathrm{c}}=0 \\
0.6508-0.3436 \lg f_{\mathrm{c}} & 0 \triangleleft f_{\mathrm{c}} \triangleleft 0.783, \\
0 & f_{\mathrm{c}}=0.783\end{cases} \\
& f_{\mathrm{c}}=\left(\mathrm{NDVI}-\mathrm{NDVI}_{\mathrm{soil}}\right) /\left(\mathrm{NDVI}_{\mathrm{veg}}-\mathrm{NDVI}_{\mathrm{soil}}\right), \\
& \mathrm{NDVI}=\left(\rho_{\mathrm{NIR}}-\rho_{\mathrm{R}}\right) /\left(\rho_{\mathrm{NIR}}+\rho_{\mathrm{R}}\right),
\end{aligned}
$$

where $C$ refers to the vegetation coverage factor, $f_{\mathrm{c}}$ refers to the vegetation coverage (\%), and NDVI refers to the normalized differential vegetation index. In this paper, the cumulative percentages of 5 and $95 \%$ are used as the confidence intervals to determine the corresponding pixel values and the effective $\mathrm{NDVI}_{\text {soil }}$ and $\mathrm{NDVI}_{\mathrm{veg}}$ in the study area. $\rho_{\mathrm{NIR}}$ refers to the near-infrared band, and $\rho_{\mathrm{R}}$ refers to the red band. The above formula is used to calculate the vegetation coverage distribution map in different periods (Fig. 3d, e, f).

\subsubsection{Conservation practice factor $(P)$}

The soil and water conservation factor $P$ refers to the percentage of soil loss to planting down the slope after adopting soil and water conservation measures. The obtained value is within $0-1$. If the value is 0 , then the area is not affected by soil erosion; if the value is 1 , the area has not been subjected to any soil or water conservation measures (Table 2).

\subsection{Calculation of the soil erosion and evaluation methods}

The above factor layers are converted into raster layers in $30 \times 30 \mathrm{~m}$ equal coordinates with ArcGIS 10.0 software. All of the layers are multiplied to obtain the spatial distribution of the soil erosion modulus in the study area. Reference SL190-2007 criteria are used for the classification and grading of soil erosion intensity relative to water erosion grading standards for Yinjiang County (Fig. 4). On this basis, the spatial and temporal evolution of soil erosion in the study area was analyzed and evaluated.

\section{Results}

\subsection{Evolution of soil erosion}

From 2000 to 2013, the total amount of soil erosion in Yinjiang decreased from $477.48 \times 10^{4} \mathrm{ta}^{-1}$ in 2000 to $366.56 \times$ $10^{4} \mathrm{ta}^{-1}$ in 2005 and $314.64 \times 10^{4} \mathrm{ta}^{-1}$ in 2013 , with a total reduction of $34.11 \%$ (Table 3 ).

The area of micro-erosion accounts for 28.97, 30.27, and $34.21 \%$ of the total erosion area in the three study periods, with a total increase of $5.24 \%$. The area of mild erosion accounts for $39.99,43.90$, and $44.29 \%$ of the total erosion area; the area decreased by $1860 \mathrm{hm}^{2}$ overall within the study period, but mild erosion conversion led to an increase of $4.30 \%$. The total of micro-erosion and mild erosion in the three periods was more than $65 \%$, and the moderate to higher levels for 2000 to 2013 are declining. The decreased amplitudes of moderate erosion areas, strong erosion areas, pole strong erosion areas, and violent erosion areas were $24,49,63$, and $89 \%$, respectively. Yinjiang County exhibited a transformation from moderate erosion, strong erosion, pole strong erosion, and violent erosion to micro-erosion and mild erosion.

The percentages of micro-erosion, mild erosion, and moderate erosion to the total erosion amount increased during the study period. Mild and moderate erosion amounts contributed to the total erosion amount in Yinjiang County. The total percentage of erosion increased from $57.14 \%$ in 2000 to $71.63 \%$ in 2013 , whereas the percentages of strong, pole strong, and violent erosion significantly decreased. The total percentage of strong and pole strong erosion decreased from 36.15 to $24.33 \%$.

In summary, Yinjiang County was mainly affected by mild and moderate erosion. The total percentage of soil erosion increased by $12.57 \%$ from 2000 to 2013. In the entirety of Yinjiang County, a large portion of land experienced microerosion and mild erosion in 2000, 2005, and 2013. The total erosion was more than $65 \%$. The corresponding soil erosion accounted for $28.21,34.66$, and $40.78 \%$ of the total erosion. Although the total area affected by erosion increased to $2374 \mathrm{hm}^{2}$, the areas with more than micro-erosion levels decreased. The erosion amount decreased yearly, and the erosion level significantly changed from high to low over a large area.

\subsection{Grade shifting of soil erosion intensity}

From 2000 to 2005, the percentages of areas with unchanged soil erosion intensity, increased soil erosion intensity, and decreased erosion intensity were $22.76,33.68$, and $43.56 \%$, respectively. Hence, the soil erosion level was transformed from moderate and high levels to low levels during the study period (Fig. 5).

From 2005 to 2013, the percentage of area with unchanged soil erosion intensity was $23.19 \%$, which increased by $0.43 \%$ relative to $2000-2005$. The percentage of areas 
Table 2. Soil and water conservation factors in Yinjiang County.

\begin{tabular}{|c|c|c|c|c|c|c|c|c|c|}
\hline $\begin{array}{l}\text { Land use } \\
\text { types }\end{array}$ & Forest & Grassland & Cropland & $\begin{array}{r}\text { Paddy } \\
\text { field }\end{array}$ & Town & Village & Road & Water & $\begin{array}{r}\text { Unused } \\
\text { land }\end{array}$ \\
\hline$p$ & 1 & 1 & 0.4 & 0.15 & 0 & 0 & 0 & 0 & 1 \\
\hline
\end{tabular}
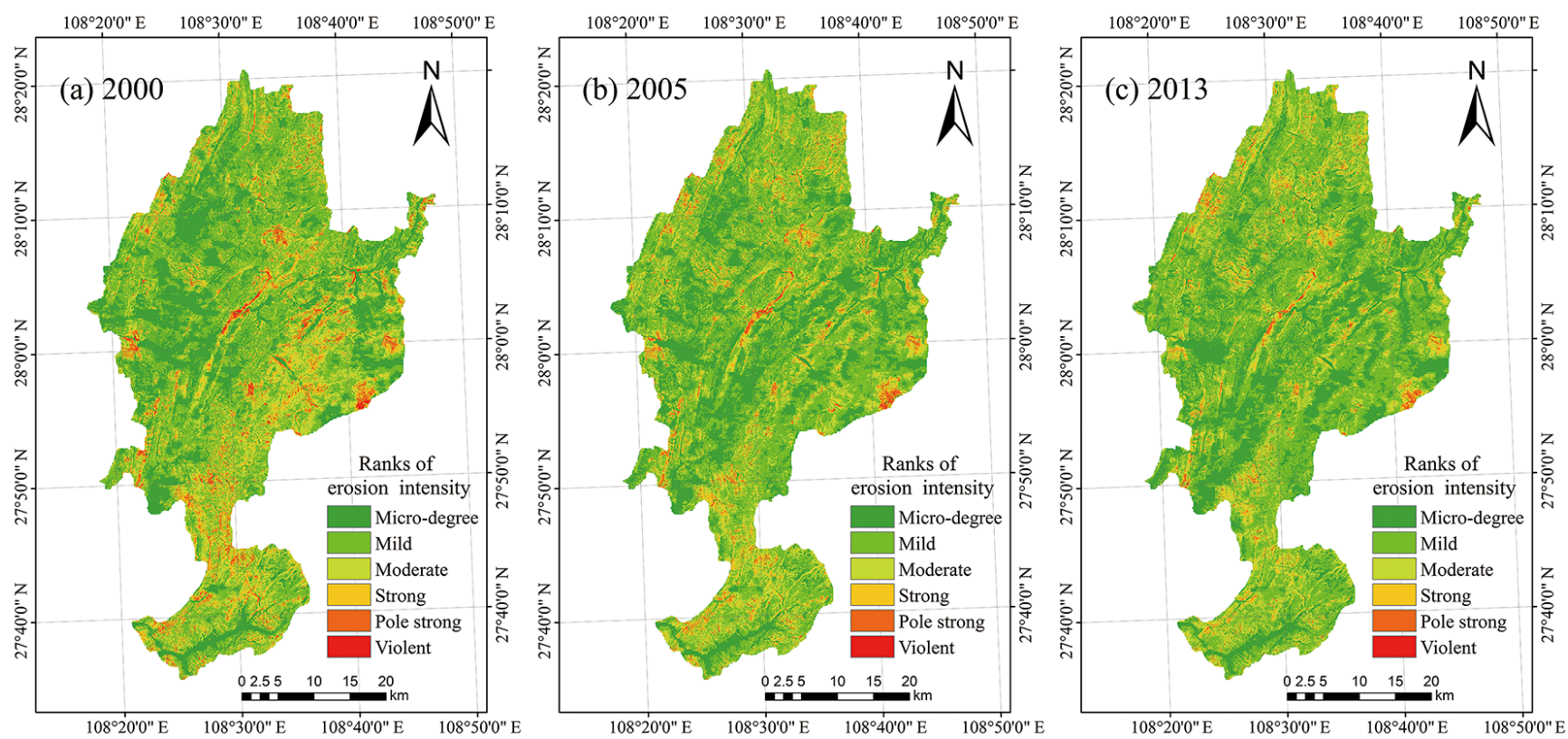

Figure 4. Spatial distribution of soil erosion in Yinjiang in different periods.

with increased and decreased soil erosion intensity slightly increased and attained values of $40.2 \%$ and $36.59 \%$, respectively.

From 2000 to 2013, the percentages of the total area with increased and decreased erosion intensity were 31.6 and $48.66 \%$, respectively. This finding reveals that soil erosion intensity has an improving trend.

\subsection{Spatial variation in soil erosion}

\subsubsection{Different slope zones}

Slope is the most important terrain factor that influences soil erosion, and it is related to the soil erosion modulus; the modulus in Yinjiang County gradually increased with increasing slope. Hence, slope exhibits a significantly positive correlation with the soil erosion modulus. High-slope areas possess a high mean soil erosion modulus but a small erosion area and erosion amount (Fig. 6).

The soil erosion area of $33.31 \%$ represents the largest area within $15-25^{\circ}$ slope bands, followed by $25-35^{\circ}$ slope bands (area of $27.28 \%$ ). The $25-35,15-25,8-15$, and 5-8 $8^{\circ}$ slope bands account for $20.71,19.68,18.09$, and $17.32 \%$ of the total erosion. The band with a slope $<5^{\circ}$ represents the lowest erosion amount, accounting for $10.85 \%$ (Table 4 ). All of the slope bands exhibit a slight erosion level in terms of the mean erosion modulus.

\subsubsection{Outcrop area of different rocks}

The karst surface is broken and contains peak clusters, needle karst, and isolated peaks. The area with carbonate rock distribution accounts for $60.06 \%$ of the total study area. From 2000 to 2013, the annual erosion rate decreased by $8.22 \mathrm{t}\left(\mathrm{hm}^{2} \mathrm{a}\right)^{-1}$ with a decreased amplitude of $30.82 \%$. In non-carbonate rock areas, the annual erosion rate from 2000 to 2013 decreased by $6.19 \mathrm{t}\left(\mathrm{hm}^{2} \mathrm{a}\right)^{-1}$ with a decreased amplitude of $24.29 \%$, which is smaller than in carbonate rock areas (Fig. 7).

The annual erosion rate in the carbonate rock area from 2000 to 2013 demonstrated the following trends: erosion was reduced by $12.24 \mathrm{t}\left(\mathrm{hm}^{2} \mathrm{a}\right)^{-1}$ with a decreased amplitude of $40.40 \%$ in the homogenous dolomite (HD) area (soil loss tolerance in the area $T=20)$. It was reduced by $3.8 \mathrm{t}\left(\mathrm{hm}^{2} \mathrm{a}\right)^{-1}$ with a decreased amplitude of $15.99 \%$ in the homogenous limestone (HL) area. It was reduced by $1.28 \mathrm{t}\left(\mathrm{hm}^{2} \mathrm{a}\right)^{-1}$ with a decreased amplitude of only $5.26 \%$ in the mixed area of homogenous limestone and homogenous dolomite (MHLD). It was reduced by $4.38 \mathrm{t}\left(\mathrm{hm}^{2} \mathrm{a}\right)^{-1}$ with a decreased amplitude of $20.11 \%$ in the clastic rock area of limestone interlayer 
Table 3. The soil erosion estimates for different periods in Yinjiang.

\begin{tabular}{llrrrrr}
\hline & Erosion rating & $\begin{array}{r}\text { Erosion area } \\
\left(\mathrm{hm}^{2}\right)\end{array}$ & $\begin{array}{r}\text { Total soil loss } \\
\left(\times 10^{4} \mathrm{t}\right)\end{array}$ & $\begin{array}{r}\text { Average modulus } \\
\left(\mathrm{t} \mathrm{hm}^{-2} \mathrm{a}^{-1}\right)\end{array}$ & $\begin{array}{r}\text { Area ratio } \\
(\%)\end{array}$ & $\begin{array}{r}\text { Erosion ratio } \\
(\%)\end{array}$ \\
\hline \multirow{2}{2}{000} & 36187 & 8.47 & 2.30 & 28.97 & 1.77 \\
& Micro-degree & 87470 & 126.25 & 126 & 39.99 & 26.44 \\
& Mild & 40506 & 146.58 & 36.11 & 19.27 & 30.70 \\
& Moderate & 98.88 & 62.88 & 7.78 & 20.71 \\
& Strong & 15719 & 103.30 & 3.46 & 15.44 \\
& Pole strong & 7153 & 13.73 & 184.80 & 0.54 & 4.94 \\
\hline Violent & 1244 & 23.57 & 2.35 & 30.27 & 2.66 \\
2005 & Micro-degree & 56529 & 9.74 & 13.92 & 43.90 & 32.00 \\
& Mild & 84898 & 117.30 & 35.23 & 17.76 & 32.99 \\
& Moderate & 34362 & 120.91 & 62.17 & 5.65 & 18.54 \\
& Strong & 10929 & 67.95 & 102.70 & 2.25 & 12.19 \\
& Pole strong & 4352 & 44.67 & 177.59 & 0.17 & 1.64 \\
\hline Violent & 338 & 5.99 & 2.32 & 34.21 & 3.36 \\
\hline \multirow{2}{*}{2013} & Micro-degree & 63544 & 10.57 & 13.83 & 44.29 & 37.42 \\
Mild & 85610 & 117.63 & 34.97 & 15.92 & 34.21 \\
Moderate & 30801 & 107.54 & 62.11 & 4.14 & 15.82 \\
Strong & 8010 & 49.73 & 100.52 & 1.38 & 8.51 \\
Pole strong & 2663 & 26.76 & 168.55 & 0.06 & 0.67 \\
Violent & 125 & 2.11 & &
\end{tabular}
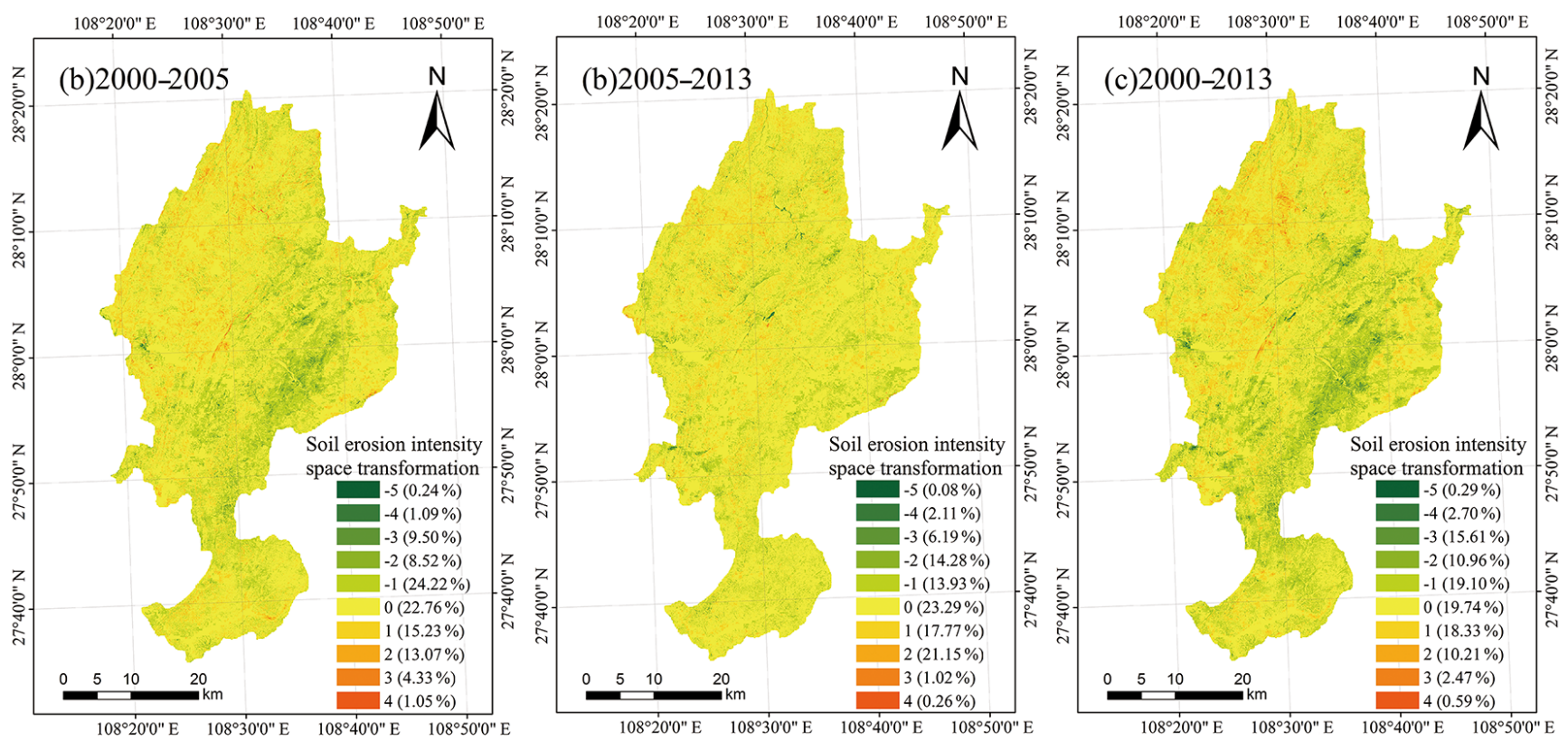

Figure 5. The intensity variation map of the soil erosion in Yinjiang. Note: 0 refers to unchanged soil erosion intensity; 1 refers to the soil erosion intensity increasing by one level; 2 refers to the soil erosion intensity increasing by two levels; 3 refers to the soil erosion intensity increasing by three levels; 4 refers to the soil erosion intensity increasing by four levels; 5 refers to the soil erosion intensity increasing by five levels; -1 refers to the soil erosion intensity decreasing by one level; -2 refers to the soil erosion intensity decreasing by two levels; -3 refers to the soil erosion intensity decreasing by three levels; -4 refers to the soil erosion intensity decreasing by four levels; and -5 refers to the soil erosion intensity decreasing by five levels. 

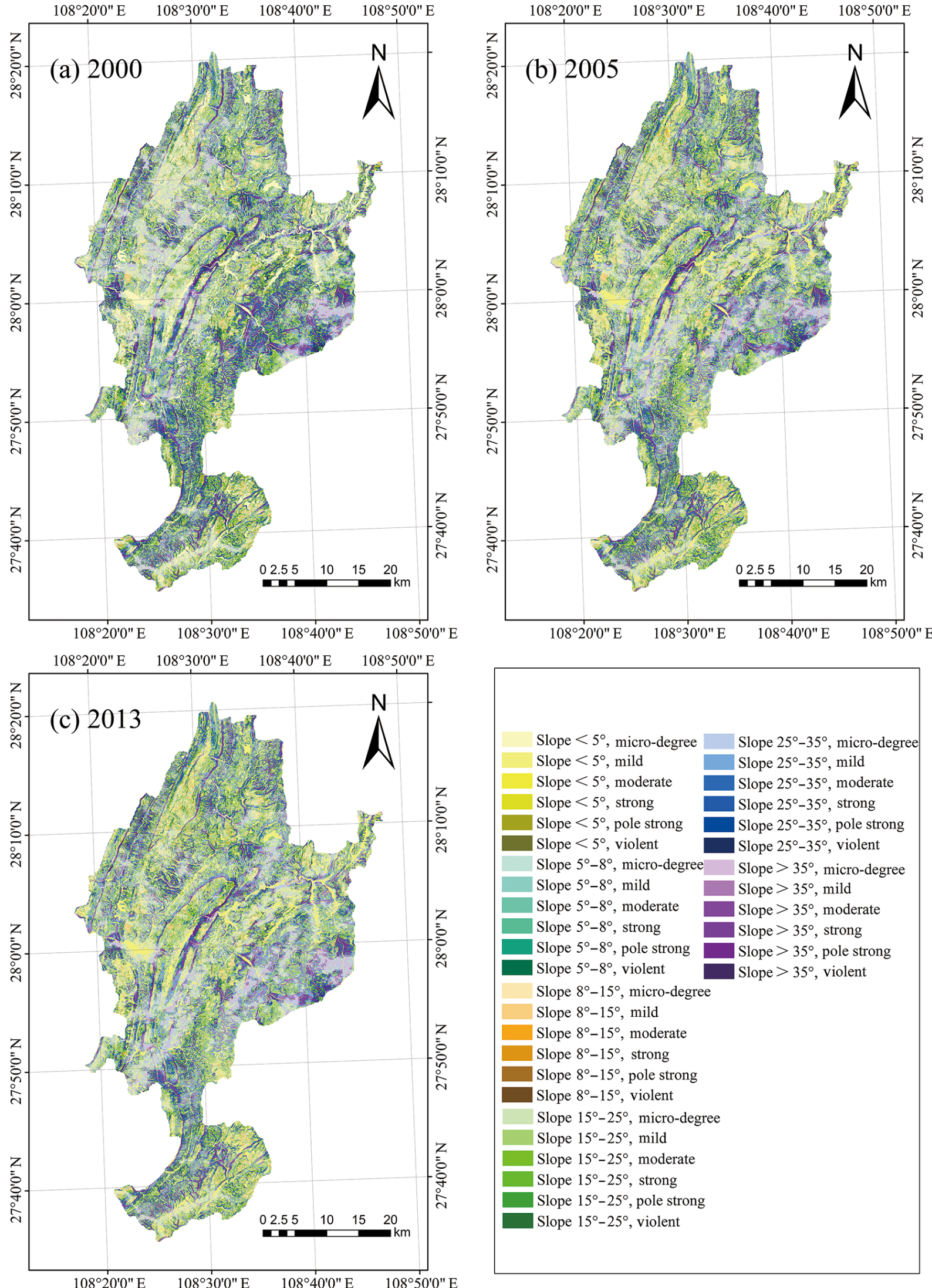

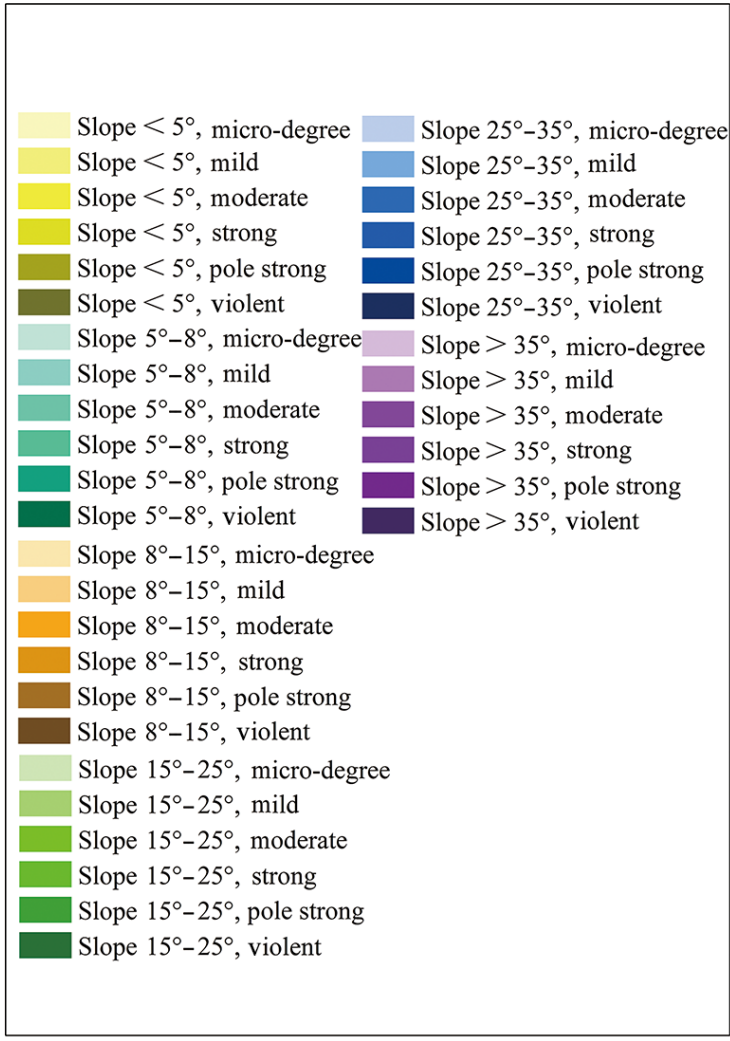

Figure 6. Spatial distribution of soil erosion in different slope bands. 

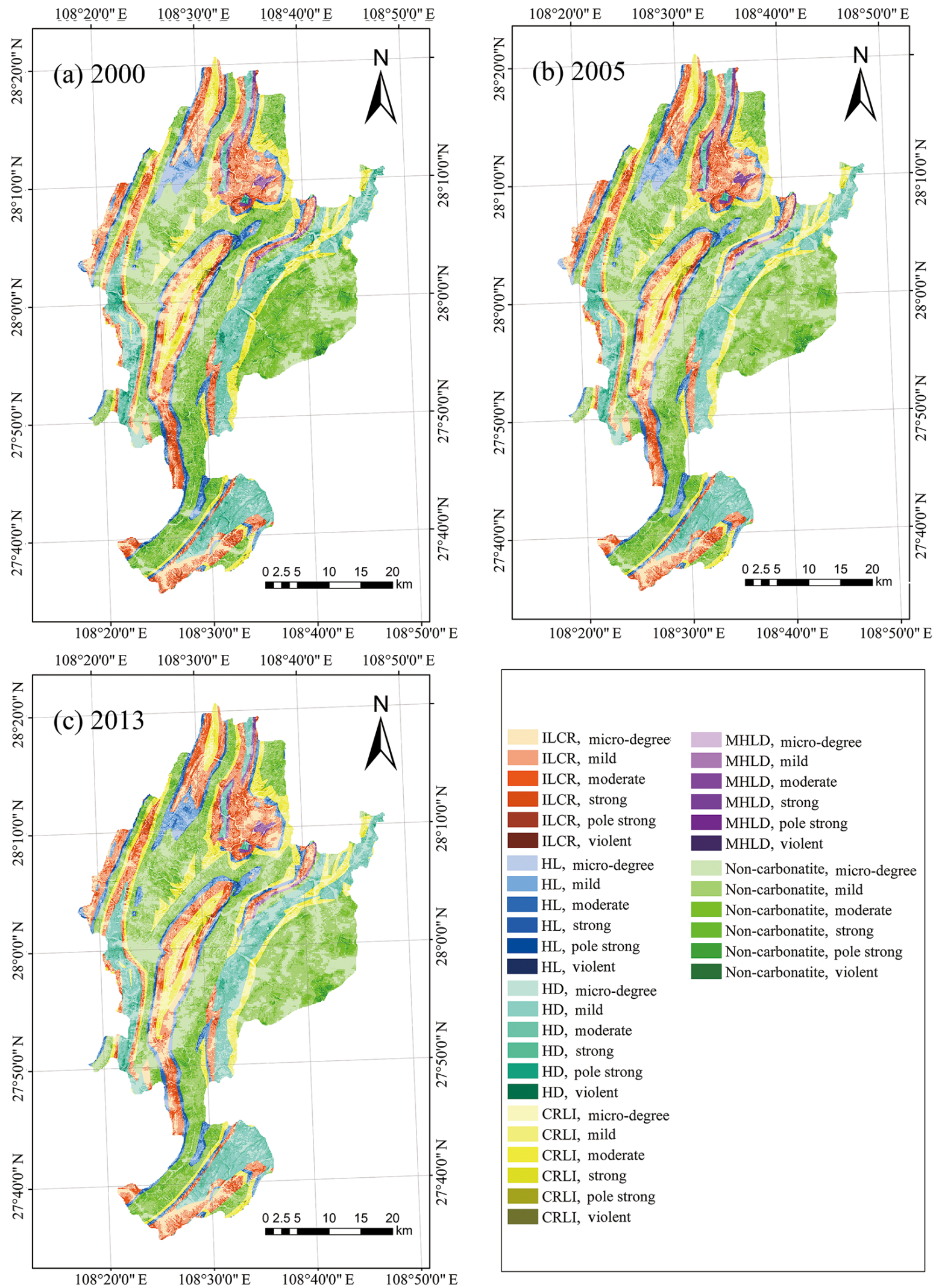

\begin{tabular}{|l|l|}
\hline & \\
& \\
ILCR, micro-degree & MHLD, micro-degree \\
\hline ILCR, mild & MHLD, mild \\
ILCR, moderate & MHLD, moderate \\
ILCR, strong & MHLD, strong \\
ILCR, pole strong & MHLD, pole strong \\
ILCR, violent & MHLD, violent \\
\hline HL, micro-degree & Non-carbonatite, micro-degree \\
HL, mild & Non-carbonatite, mild \\
\hline HL, moderate & Non-carbonatite, moderate \\
HL, strong & Non-carbonatite, strong \\
HL, pole strong & Non-carbonatite, pole strong \\
HL, violent & Non-carbonatite, violent \\
\hline HD, micro-degree & \\
HD, mild & \\
HD, moderate & \\
HD, strong & \\
HD, pole strong & \\
HD, violent & \\
CRLI, micro-degree & \\
CRLI, mild & \\
CRLI, moderate \\
CRLI, strong \\
CRLI, pole strong \\
CRLI, violent \\
\hline \\
\hline
\end{tabular}

Figure 7. Spatial distribution of soil erosion in different rock outcrop areas. 

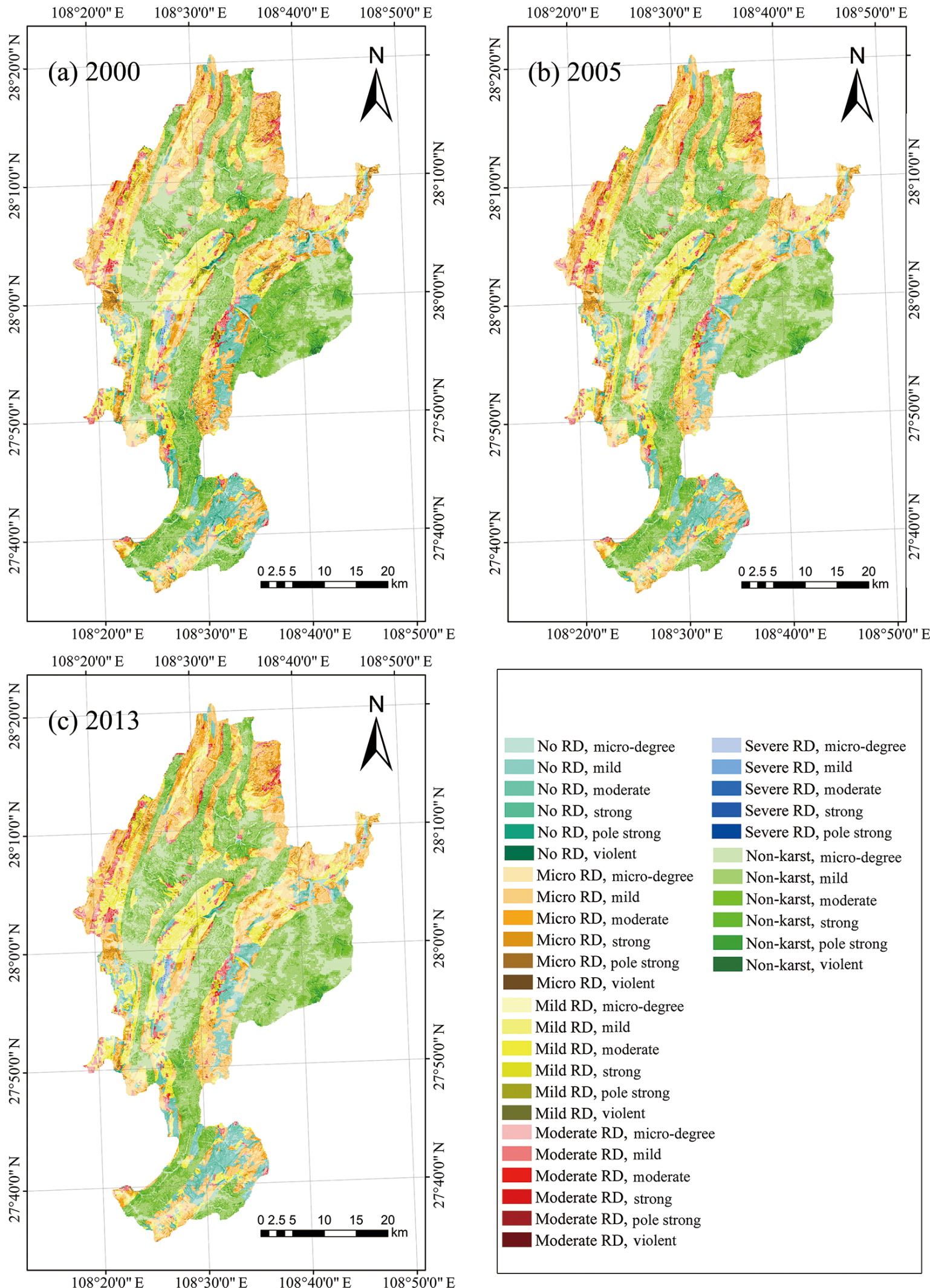

\begin{tabular}{|l|l|}
\hline & \\
& \\
& \\
No RD, micro-degree & Severe RD, micro-degree \\
\hline No RD, mild & Severe RD, mild \\
\hline No RD, moderate & Severe RD, moderate \\
\hline No RD, strong & Severe RD, strong \\
\hline No RD, pole strong & Severe RD, pole strong \\
\hline No RD, violent & Non-karst, micro-degree \\
\hline Micro RD, micro-degree & Non-karst, mild \\
\hline Micro RD, mild & Non-karst, moderate \\
\hline Micro RD, moderate & Non-karst, strong \\
\hline Micro RD, strong & Non-karst, pole strong \\
\hline Micro RD, pole strong & Non-karst, violent \\
\hline Micro RD, violent & \\
\hline Mild RD, micro-degree & \\
Mild RD, mild & \\
\hline Mild RD, moderate & \\
\hline Mild RD, strong & \\
\hline Mild RD, pole strong & \\
\hline Mild RD, violent & \\
\hline Moderate RD, micro-degree & \\
\hline Moderate RD, mild & \\
\hline Moderate RD, moderate & \\
\hline Moderate RD, strong & \\
\hline Moderate RD, pole strong & \\
\hline Moderate RD, violent & \\
\hline
\end{tabular}

Figure 8. Spatial distribution of soil erosion on different rocky desertification grades. 
Table 4. Soil erosion conditions on different slope grades.

\begin{tabular}{lrrr}
\hline Slope & $\begin{array}{r}\text { Average modulus } \\
\left(\mathrm{t} \mathrm{hm}^{-2} \mathrm{a}^{-1}\right)\end{array}$ & $\begin{array}{r}\text { Area ratio } \\
(\%)\end{array}$ & $\begin{array}{r}\text { Erosion ratio } \\
(\%)\end{array}$ \\
\hline$<5^{\circ}$ & 15.32 & 9.68 & 10.85 \\
$5-8^{\circ}$ & 13.31 & 4.76 & 17.32 \\
$8-15^{\circ}$ & 15.33 & 12.94 & 18.09 \\
$15-25^{\circ}$ & 17.56 & 33.31 & 19.68 \\
$25-35^{\circ}$ & 18.54 & 27.28 & 20.72 \\
$>35^{\circ}$ & 20.15 & 12.03 & 13.33 \\
\hline
\end{tabular}

(CRLI; soil loss tolerance in the area $T=100$ ), and it was reduced by $4.31 \mathrm{t}\left(\mathrm{hm}^{2} \mathrm{a}\right)^{-1}$ with a decreased amplitude of $17.07 \%$ in the interbedded area of limestone and clastic rock (ILCR; soil loss tolerance in the area $T=250$ ) (Table 5).

The relationship of the changes in the decreased amplitude in the study period was as follows: homogenous dolomite $(T=20)>$ clastic rock of limestone interlayer $(T=100)$ $>$ interbedded of limestone and clastic rock $(T=250)>$ homogenous limestone $>$ mixture of homogenous limestone and dolomite.

\subsubsection{Different grades of rocky desertification}

Different degrees of rocky desertification are distributed in approximately $57.69 \%$ of the study area. In the karst area, interference and destruction from invasive social and economic activities caused severe soil erosion, leading to soil particle loss, a thin soil layer, and outcropped base rock in the desertification area (Fig. 8).

From 2000 to 2013, the annual erosion rate in Yinjiang County exhibited the following trend: erosion was reduced by $11.99 \mathrm{t}\left(\mathrm{hm}^{2} \mathrm{a}\right)^{-1}$ with a decreased amplitude of $39.36 \%$ in the non-rocky desertification area. It was reduced by $6.23 \mathrm{t}\left(\mathrm{hm}^{2} \mathrm{a}\right)^{-1}$ with a decreased amplitude of $24.53 \%$ in the micro-rocky desertification area. It was reduced by $3.2 \mathrm{t}\left(\mathrm{hm}^{2} \mathrm{a}\right)^{-1}$ with a decreased amplitude of $14.90 \%$ in the mild rocky desertification area. It was reduced by $1.68 \mathrm{t}\left(\mathrm{hm}^{2} \mathrm{a}\right)^{-1}$ with a decreased amplitude of $9.06 \%$ in the moderate rocky desertification area. It increased by $1.86 \mathrm{t}\left(\mathrm{hm}^{2} \mathrm{a}\right)^{-1}$ with an increased amplitude of $19.16 \%$ in the severe rocky desertification area, and it was reduced by $7.42 \mathrm{t}\left(\mathrm{hm}^{2} \mathrm{a}\right)^{-1}$ with a decreased amplitude of $28.62 \%$ in the non-rocky desertification area (Table 6).

The relationship of the decreasing amplitude of erosion rates in karst areas during the study period was as follows: non-rocky desertification area $>$ micro-rocky desertification area $>$ mild rocky desertification area $>$ moderate rocky desertification area $>$ severe rocky desertification area. The soil erosion amounts decreased in the non-rocky desertification area, micro-rocky desertification area, mild rocky desertification area, and moderate rocky desertification area; they increased in the severe rocky desertification area. The microrocky desertification zone occupied the largest soil erosion area $(47.55 \%$ of the total area) and had the highest erosion amount ( $48.86 \%$ of the total erosion amount). The mean erosion modulus was a mild level of erosion.

\section{Discussion}

\subsection{Spatiotemporal evolution characteristics of soil erosion}

The overall soil erosion conditions in Yinjiang County improved annually. The erosion area and erosion amount were distinguished by conversion from strong, pole strong, and violent erosion to moderate and lower levels of erosion. This phenomenon occurred because rainfall and vegetation coverage mainly affect the dynamic changes in soil erosion in Yinjiang County. On the one hand, rainfall decreased yearly from $1121.03 \mathrm{~mm}$ in 2000 to $734.39 \mathrm{~mm}$ in 2013 in the study period, which led to a weakening of rainfall erosion (Mohamadi and Kavian, 2015). On the other hand, Yinjiang County has a wide range of farmland returning to forests and closed forest projects, so vegetation management and soil and water conservation measures in the study area correspondingly changed. The improved vegetation coverage plays a role in the prevention and control of soil and water erosion. Soil and water conservation measures have a large-scale active effect and cause significant results.

Slope determines the speed of surface runoff. If other factors remain unchanged, the surface runoff impacts on soil in an area with a slope below $35^{\circ}$ become stronger and the soil erosion amount increases with increasing slope. When the slope reaches $35^{\circ}$, the erosion amount decreases and is weakly influenced by the increasing slope. The band with a slope of $15-35^{\circ}$ accounts for $60.59 \%$ of the total erosion area and $40.44 \%$ of the total erosion amount. This band is the main erosion slope section in the study area. This phenomenon is the result of artificial reclamation in the slope area. Based on the current results, as has been reported in previous studies (Xu et al., 2008; Chen et al., 2012), the slope is about $25^{\circ}$ in areas prone to soil erosion. The $15-35^{\circ}$ slope area in Yinjiang County must have enhanced prevention and control measures for soil erosion.

\subsection{Influence of spatial factors on soil erosion}

\subsubsection{Influence of lithology on soil erosion}

The decreasing amplitude of the soil erosion rate in the carbonate area was larger than in the non-carbonate area. This finding is related to the widely distributed rocky desertification in the karst area, soil formation rate, soil type, and other factors. After the carbonate rock is dissolved in the study area, soluble matter is removed by water, and insoluble matter forms soil. The content of insoluble matter in carbonate rock in the southwest is 1-9\% and is generally less than $5 \%$. The soil-forming efficiency is low. After erosion and weath- 
Table 5. Annual erosion rates in different rock outcrop areas.

\begin{tabular}{rrrrrrrr}
\hline & \multicolumn{7}{c}{ Average soil erosion rate $\left(\mathrm{t} \mathrm{hm}^{-2} \mathrm{a}^{-1}\right)$} \\
\cline { 2 - 8 } & Non-carbonatite & carbonatite & HD & HL & MHLD & CRLI & ILCR \\
\hline 2000 & 26.67 & 25.48 & 30.30 & 23.77 & 24.34 & 21.78 & 25.25 \\
2005 & 21.79 & 21.82 & 22.26 & 21.86 & 27.44 & 19.10 & 23.03 \\
2013 & 18.45 & 19.29 & 18.06 & 19.97 & 23.06 & 17.40 & 20.94 \\
\hline
\end{tabular}

Table 6. Annual erosion rates in different rocky desertification grades.

\begin{tabular}{rrrrrrr}
\hline & \multicolumn{6}{c}{ Average soil erosion rate $\left(\mathrm{thm}^{-2} \mathrm{a}^{-1}\right)$} \\
\cline { 2 - 7 } & No RD & Micro RD & Mild RD & Moderate RD & Severe RD & Non-karst \\
\hline 2000 & 30.46 & 25.40 & 21.48 & 18.54 & 9.71 & 25.93 \\
2005 & 22.17 & 21.79 & 20.09 & 18.57 & 8.98 & 21.74 \\
2013 & 18.47 & 19.17 & 18.28 & 16.86 & 11.56 & 18.51 \\
\hline
\end{tabular}

ering, $630-7880 \mathrm{ka}$ of carbonate is required to form a $1 \mathrm{~m}$ thick soil layer. The soil-forming rate is $10-40$ times slower than in the general non-karst area (Chen, 1997). Moreover, the soil-forming rate and soil thickness are higher in noncarbonate areas than in carbonate areas. The formation time of runoff is short after rainfall, and the surface water storage capacity is low in the karst area. Rainfall forms underground runoff; hence, underground soil loss is high and the vegetation coverage is lower than in the non-karst area.

In the study period, only $10-22.37 \%$ of the areas are within the allowable loss amount. These areas are mainly distributed in the valley zone, with low altitudes in the south of Yinjiang and the smooth zone in the southwestern and Fanjingshan areas. These areas are mostly located in non-karst zones with a wide distribution of non-carbonates. The soil formation is rapid, the underground soil loss is low, and the vegetation coverage is high.

Soil erosion exhibited an improving trend in different outcrop areas. However, the dynamic changes in soil erosion in various lithological distribution belts were significant. The decreasing amplitude of the annual erosion rate in homogenous dolomite, limestone intercalated with clastic rock, and the interbedded region of limestone and clastic rock gradually decreased with decreasing carbonate content. This phenomenon occurred because of the mineral composition and chemical characteristics of the parent rock, which directly affect the speed and direction of soil formation. The weathering degree of different lithologies, the speed and direction of soil formation, and the erosion type, intensity, and rate are also different. If the carbonate content is high, then the soil formation rate is slow and the soil layer is shallow. Therefore, the decreasing amplitude of the annual erosion rate is low. The homogenous limestone region and the mixed region of homogenous dolomite and limestone are mainly distributed in an area of low altitude with a slope of less than $8^{\circ}$. There is therefore a specific soil thickness, resulting in a large erosion model and small decreasing amplitude of the annual erosion rate. Moreover, the lithology controls the spatial distribution and development of soil erosion. Li et al. (2006) reported that

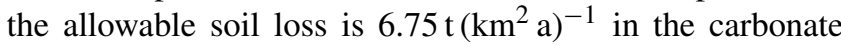
area and $7.08 \mathrm{t}\left(\mathrm{km}^{2} \mathrm{a}\right)^{-1}$ in the homogenous limestone area and homogenous dolomite area. The rank of allowable loss amounts is as follows: homogenous dolomite composition distribution area $>$ homogenous limestone composition distribution area. In the present study, the rank of calculated loss amounts (homogenous dolomite area $>$ homogenous limestone area) is consistent with a previous study. The allowable soil loss amounts are $45.40 \mathrm{t}\left(\mathrm{km}^{2} \mathrm{a}\right)^{-1}$ in limestone intercalated with clastic rock and $103.38 \mathrm{t}\left(\mathrm{km}^{2} \mathrm{a}\right)^{-1}$ in the interbedded region of limestone and clastic rock. The relationship of the allowable loss amount is as follows: interbedded region of limestone and clastic rock > limestone intercalated with clastic rock. The allowable loss is positively correlated with the amount of loss calculated in areas of $T=100$ (limestone intercalated with clastic rock) and $T=250$ (interbedded layer of limestone and clastic rock).

\subsubsection{Effects of rocky desertification on soil erosion}

In terms of soil erosion intensity in the study area, the decreasing amplitude in the annual soil erosion rate gradually decreases with the aggravation of rocky desertification. When the degree of rocky desertification is high, the erosion modulus is low and the decreasing amplitude of the annual erosion rate is small. The decreasing amplitude of the annual erosion rate in non-rocky desertification areas is higher than in rocky desertification areas. This finding could be because the non-rocky desertification areas are mainly distributed in valleys and low-altitude regions with sufficient soil thickness and good vegetation coverage. Currently, the soil erosion rate in the severe rocky desertification region of the study area is 
Table 7. Soil erosion data obtained in previous studies in typical karst areas.

\begin{tabular}{llrrr}
\hline Reference & Study area & Timescale & $\begin{array}{r}\text { Average modulus } \\
\left(\mathrm{t} \mathrm{hm}^{-2} \mathrm{a}^{-1}\right)\end{array}$ & $\begin{array}{r}\text { Total soil loss } \\
\left(\times 10^{4} \mathrm{t}\right)\end{array}$ \\
\hline Zeng et al. (2014) & Hongfeng Lake watershed & $1960-1986$ & 38.35 & 610.53 \\
& & $1987-1997$ & 52.80 & 839.90 \\
& & $1998-2004$ & 40.24 & 640.18 \\
Xu and Peng (2008) & Maotiao River watershed & 2002 & 28.70 & 875.65 \\
Y. Wang et al. (2014) & Wujiang River basin & $1980-1989$ & 26.78 & 133.36 \\
& & $1990-1999$ & 23.13 & 115.18 \\
This paper & Yinjiang County & 2000 & 25.09 & 477.49 \\
& & 2005 & 21.53 & 366.56 \\
& & 2013 & 18.84 & 314.64 \\
\hline
\end{tabular}

increasing and the loss intensity is large; however, they were not obvious in general (the total amount of soil erosion is small and very low). As these areas, which are concentrated in the Langxi valley, are small areas with poor conditions for growing vegetation, are in a soil accumulation environment, or are on negative terrain, there are specific soil thicknesses causing high erosion rates.

The decrease in the erosion rate in other rocky desertification bands reveals that soil erosion in the rocky desertification area improved during the study period. The soil loss in the karst rocky desertification areas could be due to the particular geology (wide distribution of carbonate rocks), topography (presence of underground space), vegetation, and climate conditions, which lead to a low soil formation rate and shallow soil layer in the study area. Abundant rainfall in the study area provides a dynamic potential for soil and water loss. Furthermore, underground pores, cracks, and pipes are widely distributed in the karst area. In addition to surface loss, soil loss also occurs through karst caves, underground rivers, and other means (Peng and Wang, 2012; J. Wang et al., 2014).

The current study method exhibits certain limitations in a typical karst area. In future studies, underground soil and water loss in the karst area should be calculated. The localization of the model calculation factor in the karst area should also be considered for calculating soil erosion using the proposed model. Based on the specificity of soil erosion in the karst area, improving the method and exploring erosion indicators can improve and enrich the study of soil erosion in karst areas.

\subsection{Modulus of different soil erosion statistics in karst areas}

The RUSLE model is a classical model for evaluating soil erosion and is widely used in various countries and regions worldwide. Although the RUSLE model is a mature and classical model, its application in karst areas is relatively scarce. Several scientists have conducted research on different parts of the karst areas in Guizhou Province. Different results have been derived; thus, a simple control should be adopted. The results are given in Table 7 .

\section{Conclusions}

The temporal and spatial variation in soil erosion gradually declined in the study area and exhibited a changing trend from moderate and higher levels to lower levels. Slope was the most important topographic factor that affected different spatial and temporal distributions of soil erosion. The band with a slope of $15-35^{\circ}$ was the main erosion slope section in the study area. The soil erosion in all rocky outcrop areas exhibited an improving trend, but the dynamic changes in soil erosion in each lithological distribution zone varied greatly. As rocky desertification worsens, the erosion modulus lowers and the decreasing rate of annual erosion will slow.

In karst areas, lithology and rocky desertification are the most important natural factors that cause different temporal and spatial variations in soil erosion. Lithology is the geological basis of soil erosion, and rocky desertification is widely distributed in karst valley areas. Different spatial distributions of lithology and rocky desertification lead to a large area of soil loss. Lithological and rocky desertification factors introduced in the soil erosion model can accurately reflect and predict soil erosion conditions and spatial distribution characteristics in karst areas. This finding will help promote research into soil erosion in karst areas worldwide.

In karst areas, underground space is complicated and consists of multiple geological and geomorphological features. In addition to surface loss, soil loss occurs through karst caves, underground rivers, and other means, causing differences between the measured soil loss and the calculated value in the model. Most of the time, soil erosion study methods and indicators that are used for non-karst areas cannot reflect the actual conditions of karst areas.

Data availability. No data sets were used in this article. 
Competing interests. The authors declare that they have no conflict of interest.

Acknowledgements. This research was supported by the National Key Research Program of China (nos. 2016YFC0502300, 2016YFC0502102, 2013CB956700, and 2014BAB03B02), the UNESCO Research Center on Karst (no. U1612441), international cooperation research projects of the National Natural Science Fund Committee (nos. 41571130074 and 41571130042 ), the Science and Technology Plan of Guizhou Province of China (nos. 2012-6015, 2013-3190, and 2017-2966), and science and technology cooperation projects (no. 2014-3).

Edited by: Antonio Jordán

Reviewed by: four anonymous referees

\section{References}

Arnhold, S., Lindner, S., Lee, B., Martin, E., Kettering, J., and Nguyen, T. T.: Conventional and organic farming: soil erosion and conservation potential for row crop cultivation, Geoderma, 219-220, 89-105, https://doi.org/10.1016/j.geoderma.2013.12.023, 2014.

Bai, X. Y., Zhang, X. B., Long, Y., Liu, X., and Zhang, S.: Use of ${ }^{137} \mathrm{cs}$ and ${ }^{210} \mathrm{pb}$ ex, measurements on deposits in a karst depression to study the erosional response of a small karst catchment in southwest china to land-use change, Hydrol. Process., 27, 822829, https://doi.org/10.1002/hyp.9530, 2013a.

Bai, X. Y., Wang, S. J., and Xiong, K. N.: Assessing spatialtemporal evolution processes of karst rocky desertification land: indications for restoration strategies, Land Degrad. Dev., 24, 4756, https://doi.org/10.1002/ldr.1102, 2013b.

Bai, Z. G. and Wan, G. J.: Study on watershed erosion rate and its environmental effects in Guizhou Karst region, Journal of Soil Erosion and Soil and Water Conservation, 4, 1-7, 1998.

Biswas, S. S. and Pani, P.: Estimation of soil erosion using rusle and gis techniques: a case study of barakar river basin, jharkhand, india, Modeling Earth Systems and Environment, 1, 1-13, https://doi.org/10.1007/s40808-015-0040-3, 2015.

Borrelli, P., Panagos, P., Märker, M., Modugno, S., and Schütt, B.: Assessment of the impacts of clear-cutting on soil loss by water erosion in italian forests: first comprehensive monitoring and modelling approach, Catena, 149, 770-781, https://doi.org/10.1016/j.catena.2016.02.017, 2016.

Cai, C. F., Ding, S. W., Shi, Z. H., Huang, L., and Zhang, G. Y.: Study of applying USLE and geographical information system IDRISI to predict soil erosion in small watershed, J. Soil Water Conserv., 14, 19-24, https://doi.org/10.3321/j.issn:10092242.2000.02.005, 2000.

Cai, G. Q. and Liu, J. G.: Evolution of soil erosion models in China, Progress in Geography, 22, 242-250, https://doi.org/10.3969/j.issn.1007-6301.2003.03.003, 2003.

Cao, J., Yuan, D., Groves, C., Huang, F., Hui, Y., and Qian, L. U.: Carbon fluxes and sinks: the consumption of atmospheric and soil $\mathrm{CO}_{2}$ by carbonate rock dissolution, Acta Geol. Sin.-Engl., 86, 963-972, https://doi.org/10.1111/j.1755-6724.2012.00720.x, 2012.
Chen, L., Xie, G. D., Zhang, C. S., Li, S. M., Fan, N., Zhang, C. X., Pei, S., and Ge, L. Q.: Spatial distribution characteristics of soil erosion in Lancang river basin, Resources Science, 34, 12401247, 2012.

Chen, X. P.: Research on characteristics of soil erosion in Karst mountainous region environment, Journal of Soil Erosion and Soil and Water Conservation, 3, 31-36, 1997.

Edgington, D. N., Klump, J. V., Robbins, J. A., Kusner, Y. S., Pampura, V. D., and Sandimirov, I. V.: Sedimentation rates, residence times and radionuclide inventories in lake baikal from $137 \mathrm{cs}$ and $210 \mathrm{pb}$ in sediment cores, Nature, 350, 601-604, https://doi.org/10.1038/350601a0, 1991.

Fernández, C. and Vega, J. A.: Evaluation of rusle and pesera models for predicting soil erosion losses in the first year after wildfire in nw spain, Geoderma, 273, 64-72, https://doi.org/10.1016/j.geoderma.2016.03.016, 2016.

Feng, M., Wang, Q., Hao, Q., Yin, Y., Song, Z., Wang, H., and Liu, H.: Determinants of soil erosion during the last 1600 years in the forest-steppe ecotone in northern china reconstructed from lacustrine sediments, Palaeogeogr. Palaeocl., 449, 79-84, 2016.

Feng, T., Chen, H. S., and Wang, K. G.: 137Cs profile distribution character and its implication for soil erosion on Karst slopes of Northwest Guangxi, Chinese Journal of Applied Ecology, 22, 593-599, https://doi.org/10.13287/j.1001-9332.2011.0123, 2011.

Feng, T., Chen, H., Polyakov, V. O., Wang, K., Zhang, X., and Zhang, W.: Soil erosion rates in two karst peak-cluster depression basins of northwest guangxi,china:comparison of the rusle model with ${ }^{137}$ cs measurements, Geomorphology, 253, 217224, https://doi.org/10.1016/j.geomorph.2015.10.013, 2016.

Ganasri, B. P. and Ramesh, H.: Assessment of soil erosion by RUSLE model using remote sensing and GIS-A case study of Nethravathi Basin, Geoscience Frontiers, 7, 953-961, 2016.

Gao, X., Xie, Y., Liu, G., Liu, B., and Duan, X.: Effects of soil erosion on soybean yield as estimated by simulating gradually eroded soil profiles, Soil Till. Res., 145, 126-134, https://doi.org/10.1016/j.still.2014.09.004, 2015.

Guo, Q., Hao, Y., and Liu, B.: Rates of soil erosion in china: a study based on runoff plot data, Catena, 124, 6-76, https://doi.org/10.1016/j.catena.2014.08.013, 2015.

Hancock, G. J., Wilkinson, S. N., Hawdon, A. A., and Keen, R. J.: Use of fallout tracers 7 be, $210 \mathrm{pb}$ and 137 cs to distinguish the form of sub-surface soil erosion delivering sediment to rivers in large catchments, Hydrol. Process, 28, 3855-3874, https://doi.org/10.1002/hyp.9926, 2014.

Higgitt, D.: Soil erosion and soil problems, Prog. Phys. Geog., 17, 461-472, 1993.

Karamesouti, M., Petropoulos, G. P., Papanikolaou, I. D., Kairis, O., and Kosmas, K.: Erosion rate predictions from pesera and rusle at a mediterranean site before and after a wildfire: comparison and implications, Geoderma, 261, 44-58, https://doi.org/10.1016/j.geoderma.2015.06.025, 2016.

Krklec, K., Domínguez-Villar, D., Carrasco, R. M., and Pedraza, J.: Current denudation rates in dolostone karst from central spain: implications for the formation of unroofed caves, Geomorphology, 264, 1-11, https://doi.org/10.1016/j.geomorph.2016.04.007, 2016.

Li, Y., Bai, X. Y., Zhou, Y., Qin, L., Tian, X., Tian, Y., and Li, P. L.: Spatial-temporal evolution of soil erosion in a typical moun- 
tainous karst basin in sw china, based on gis and rusle, Arab. J. Sci. Eng., 41, 1-13, https://doi.org/10.1007/s13369-015-1742-6, 2016.

Li, Y. B., Wang, S. J., Wei, C. F., and Long, J.: The spatial distribution of soil loss tolerance in carbonate area in Guizhou province, Earth of Environment, 4, 36-40, 2006.

Li, Y. B., Li, Q. Y., Luo, G. J., Bai, X. Y., Wang, Y. Y., Wang, S. J., Xie, J., and Yang, G. B.: Discussing the genesis of karst rocky desertification research based on the correlations between cropland and settlements in typical peak-cluster depressions, Solid Earth, 7, 741-750, https://doi.org/10.5194/se-7-741-2016, 2016.

Ligonja, P. J. and Shrestha, R. P.: Soil erosion assessment in kondoa eroded area in tanzania using universal soil loss equation, geographic information systems and socioeconomic approach, Land Degrad. Dev., 26, 367-379, https://doi.org/10.1002/ldr.2215, 2015.

Liu, B. Y., Nearing, M. A., Shi, P. J., and Jia, Z. W.: Slope length effects on soil loss for steep slopes, Soil Sci. Soc. Am. J., 64, 1759-1763, 2000.

Liu, Q. J., An, J., Zhang, G. H., and Wu, X. Y.: The effect of row grade and length on soil erosion from concentrated flow in furrows of contouring ridge system, Soil Till. Res., 160, 92-100, 2016.

Martínez-Casasnovas, J. A., Ramos, M. C., and Benites, G.: Soil and water assessment tool soil loss simulation at the sub-basin scale in the alt penedÈs-anoia vineyard region (ne spain) in the 2000s, Land Degrad. Dev., 27, 160-170, https://doi.org/10.1002/ldr.2240, 2016.

Mohamadi, M. A. and Kavian, A.: Effects of rainfall patterns on runoff and soil erosion in field plots, International Soil and Water Conservation Research, 3, 273-281, 2015.

Munodawafa, A.: Assessing nutrient losses with soil erosion under different tillage systems and their implications on water quality, Phys. Chem. Earth Pt. A/B/C, 32, 1135-1140, https://doi.org/10.1016/j.pce.2007.07.033, 2007.

Park, S., Oh, C., Jeon, S., Jung, H., and Choi, C.: Soil erosion risk in Korean watersheds, assessed using the revised universal soil loss equation, J. Hydrol., 399, 263-273, https://doi.org/10.1016/j.jhydrol.2011.01.004, 2011.

Peng, T. and Wang, S. J.: Effects of land use, land cover and rainfall regimes on the surface runoff and soil loss on karst slopes in southwest china, Catena, 90, 53-62, 2012.

Renard, K. G., Foster, G. R., Weesies, G. A., Mccool, D. K., and Yoder, D. C.: Predicting soil erosion by water: a guide to conservation planning with the revised universal soil loss equation (rusle), Agriculture Handbook, United States Department of Agriculture (USDA), USA, 1997.

Rickson, R. J.: Can control of soil erosion mitigate water pollution by sediments?, Sci. Total Environ., 468-469, 1187-1197, https://doi.org/10.1016/j.scitotenv.2013.05.057, 2014.

Sharpley, A. N. and Williams, J. R.: Epic-erosion/productivity impact calculator: 1. model documentation, Technical Bulletin United States Department of Agriculture, 4, 206-207, 1990.

Shi, Z. H., Cai, C. F., Ding, S. W., Wang, T. W., and Chow, T. L.: Soil conservation planning at the small watershed level using RUSLE with GIS: a case study in the Three Gorge Area of China, Catena, 55, 33-48, 2004.
Tan, B. X., Li, Z. Y., Wang, Y. H., Yu, P. T., and Liu, L. B.: Estimation of vegetation coverage and analysis of soil erosion using remote sensing data for Guishuihe drainage basin, Remote Sensing Technology and Application, 20, 215-220, 2005.

Terranova, O., Antronico, L., Coscarelli, R., and Iaquinta, P.: Soil erosion risk scenarios in the Mediterranean environment using RUSLE and GIS: an application model for Calabria (southern Italy), Geomorphology, 112, 228-245, 2009.

Tian, Y., Wang, S., Bai, X., Luo, G., and Xu, Y.: Tradeoffs among ecosystem services in a typical karst watershed, sw china, Sci. Total Environ., 566-567, 1297-1308, https://doi.org/10.1016/j.scitotenv.2016.05.190, 2016.

Wallbrink, P. J., Roddy, B. P., and Olley, J. M.: A tracer budget quantifying soil redistribution on hillslopes after forest harvesting, Catena, 47, 179-201, https://doi.org/10.1016/S03418162(01)00185-0, 2002.

Wang, J., Zou, B., Liu, Y., Tang, Y., Zhang, X., and Yang, P.: Erosion-creep-collapse mechanism of underground soil loss for the karst rocky desertification in chenqi village, puding county, guizhou, China, Environ. Earth Sci., 72, 2751-2764, 2014.

Wang, S. J. and Li, Y. B.: Problems and development trends about researches on karst rocky desertification, Adv. Earth Sci., 22, 573-582, 2007.

Wang, X., Zhao, X., Zhang, Z., Yi, L., Zuo, L., Wen, Q., Liu, F., Xu, J., Hu, S., and Liu, B.: Assessment of soil erosion change and its relationships with land use/cover change in china from the end of the 1980s to 2010, Catena, 137, 256-268, https://doi.org/10.1016/j.catena.2015.10.004, 2016.

Wang, Y., Cai, Y. L., and Pan, M.: Soil erosion simulation of the Wujiang River Basin in Guizhou Province Based on GIS, RUSLE and ANN, Geology in China, 41, 1735-1747, 2014.

Wu, L., Liu, X., and Ma, X.: Application of a modified distributeddynamic erosion and sediment yield model in a typical watershed of a hilly and gully region, Chinese Loess Plateau, Solid Earth, 7, 1577-1590, https://doi.org/10.5194/se-7-1577-2016, 2016.

$\mathrm{Xu}$, Y. Q. and Peng, J.: Effects of simulated land use change on soil erosion in the Maotiao River watershed of Guizhou Province, Resources Science, 30, 1218-1225, 2008.

Xu, Y. Q., Shao, X. M., Kong, X. B., Peng, J., and Cai, Y. L.: Adapting the rusle and gis to model soil erosion risk in a mountains karst watershed, guizhou province, china, Environ. Monit. Assess., 141, 275-286, https://doi.org/10.1007/s10661-007-9894-9, 2008.

Yang, Q., Xie, Y., Li, W., Jiang, Z., Li, H., and Qin, X.: Assessing soil erosion risk in karst area using fuzzy modeling and method of the analytical hierarchy process, Environ. Earth Sci., 71, 287292, https://doi.org/10.1007/s12665-013-2432-x, 2014.

Zeng, L. Y., Wang, M. H., and Li, C. M.: Study on soil erosion and its spatio-temporal change at Hongfeng Lake watershed based on RUSLE Model, Hydrogeology and Engineering Geology, 38, 113-118, https://doi.org/10.16030/j.cnki.issn.10003665.2011.02.003, 2014.

Zhou, F. J., Chen, M. H., and Liu, F. X.: The rainfall erosivity index in Fujian Province, Soil Water Conserv., 9, 13-18, 1995. 